\title{
Ignorance and Avoidance in EFL Written Production
}

\author{
Abdulmoneim Mahmoud \\ Department of English, College of Arts, Sultan Qaboos University \\ Muscat, Sultanate of Oman \\ E-mail: amahmoud@squ.edu.om
}

Received: July 4, 2020

Accepted: August 11, 2020

Published: August 16, 2020

doi:10.5296/ijl.v12i4.17533

URL: https://doi.org/10.5296/ijl.v12i4.17533

\begin{abstract}
This study focuses on cases where EFL students do not produce the required words and phrases in their written production (i.e. semantic nonuse). To the best of the researcher's knowledge no quantitative studies have been conducted so far to show the magnitude and the various reasons of nonuse. To fill this gap, this study attempts to quantify and analyze such instances with examples. Data were collected from 71 Arabic-to-English translations dome by university English majors as one of the tasks of an introductory course in translation. They wrote an essay in Modern Standard Arabic at the beginning of the semester and translated it into English at the end of it. Cases of nonuse where students did not use any English words were categorized and analyzed. The students were consulted to justify such cases. Accordingly, three reasons of nonuse were identified: (1) ignorance and perceived difficulty $(65 \%),(2)$ perceived redundancy (33\%), and (3) memory lapse (2\%). 'Avoidance' accounted for words and expressions that were not produced due to difficulty and redundancy. The distinction between 'ignorance' and 'avoidance' may give language instructors a deeper insight into the learners' production problems and help them in planning strategy-based teaching. The findings may also help researchers classify and explain cases of nonuse more rigorously.
\end{abstract}

Keywords: Avoidance, Communication strategies, Ignorance, nonuse, Perceived difficulty, Perceived redundancy

\section{Introduction}

Language learning and teaching in general and foreign language learning and teaching in particular has been enriched by the findings of research on learning and communication strategies. Following the shift from the traditional behaviorist and cognitive approaches to language teaching to the communicative methods based on a sociolinguistic approach, the 
1980s constituted the beginning of investigation in this area (for more information see e.g. Chuin and Kaur, 2015; Mahmoud, 2019; Sirkovic and Kovac, 2017 ). Research on learning and communication strategies also revolutionized the view towards language learners' errors and provision of corrective feedback. Learners' errors have come to be viewed as manifestations of the learning and communication strategies they use when they encounter problems in the process of learning and using the language. With the continuous flow of information about the social, psychological and cognitive processes involved in learning and communication strategies, the analysis of language learners' errors has become deeper and more sophisticated, (see e.g. Darus and Subramanian, 2009).

Researchers proposed different taxonomies of learning and communication strategies, (e.g. Aliakbari and Allvar, 2009; Llach, 2011; Mahmoud, 2013; Zhang, 2007). Almost all of these classifications share the major categories and concepts of interlingual transfer, intralingual transfer and avoidance with some differences in the terminology (e.g. compensatory strategies vs achievement strategies, translation vs borrowing), (see e.g. Alqarni, 2018; Chuin and Kaur, 2015; Zare, 2012). These taxonomies are usually prefaced with the 'avoidance' strategies as opposed to 'achievement' or 'compensatory' strategies. 'Avoidance' is used as a cover term for cases where language learners do not produce the required target form or expression due to inadequate mastery of the language. The most frequently listed types of avoidance strategies include topic avoidance, message abandonment and message adjustment, (e.g. Abu-Jamil, 2010; Elyildirim, 2017; Ghabanchi and Goudarzi, 2012; Liao and Fukuya, 2004; Siyanova and Schmitt, 2007). Most of the studies that focus exclusively on avoidance in language production were conducted a long time ago. Such studies are still relatively few compared to those that investigate the use of achievement strategies such as interlingual transfer (i.e. reliance on the first language e.g. translation) or intralingual transfer (i.e. reliance on the target language e.g. over-generalization). The present study is intended to add to the short list of avoidance studies, especially in the Arab world where English is learned as a foreign language in a formal classroom context. It seeks to find an answer as to why Arab students do not produce some words and expressions in their written EFL. It is also intended to shed light on the magnitude of this nonuse (i.e. under-representation) of EFL forms. To this end, the study takes a closer look at the key term 'avoidance' to clarify more precisely what it means when a required EFL form or expression is not produced.

\section{The Concept of Avoidance}

The word 'avoid' is defined in The Longman Dictionary of Contemporary English (1995, p.75) as "deliberately not do something, especially because it is dangerous, unpleasant, etc.". Mahmoud (2013) agrees with the other researchers (e.g. Aldukhayel, 2014) that 'avoidance' implies some kind of knowledge and having a choice. Thus, the term does not account for all cases where language learners do not produce some forms. Some words, structures and expressions may not appear in the students' language simply because they do not know them (i.e. due to ignorance) or because they believe the form is socio-culturally unacceptable (i.e. a taboo) or due to a memory lapse (i.e. a performance slip). In light of these different factors, some researchers distinguish between 'avoidance' and 'ignorance', (Mahmoud, 2013; Mattar, 2003). Accordingly, the term 'nonuse' is used in this study as a cover term for the missing 
linguistic elements for anyone of the reasons listed earlier. The term 'avoidance' is used to refer to the forms and expressions that the students know but do not produce deliberately and this is what El-Marzouk (1995) refers to as 'real' avoidance. The term 'nonuse' is so broad that it includes also cases of omission where some linguistic elements are not produced as a result of using achievement strategies such as intrelingual transfer. For example, low proficiency Arab learners of EFL drop the indefinite article 'a' or the present form of the verb 'be' (is/are) most probably due to negative interlingual transfer from Arabic where the former is represented by nunnation (the sound $/ \mathrm{n} /$ at the end of the noun) and the latter by a zero form. In this case, the lack of competence in EFL leads to the use of a compensatory strategy resulting in the nonuse of the required element. Hence, omission is a type of nonuse but different from 'avoidance' and 'ignorance'. It is one of the results of linguistic transfer which can also lead to the addition, mis-selection and mis-ordering of elements. In fact, omission is not a strategy; it is a manifestation of the use of a strategy. Therefore, omission errors are not included in this study.

It goes without saying EFL learners do not produce some forms and expressions due to perceived difficulty. Language learners may not produce the forms they deem difficult or complex grammatically, semantically or orthographically. This is a case of 'avoidance' due to the lack of confidence which is in turn due to the inadequate knowledge of the language. However, researchers need to distinguish, if possible, between actual difficulty and perceived difficulty. In the former case, the learner is sure that they will make a mistake whereas in the latter they are not sure whether the form will be correct or not. In both cases the learner 'avoids' producing a form for fear of making a mistake. Similarly, it is difficult to tell if a case of nonuse is due to ignorance or difficulty. As Mahmoud (2013, p.60) said, "One learner's difficulty could be another leaner's ignorance." Of course, not all cases of ignorance or difficulty result in nonuse. It is common for EFL learners to express their ideas in other words which could be correct or incorrect. For example, many researchers (e.g. Aldukhayel, 2014; Chen, 2007; Kharitonova, 2013; Koo, 2011; Liao and Fukuya, 2004) maintain that Arab learners of EFL 'avoid' phrasal verbs and use single-word verbs instead or use the active voice instead of the passive. Since these two structures exist in modern standard Arabic (MSA), their nonuse is most probably due to complexity and the resulting alternative structure could be correct. However, the nonuse of phrasal verbs could also be due to ignorance since they are not systematically taught like the passive voice. For the purpose of the present study, such cases of nonuse are not included since the students adopt a "risk avoidance" strategy (Elyildirim, 2017, p.232) or "evasive strategy" (Vazques, 2005, p. 69) to achieve their communicative goal by using alternative target language forms and expressions which could be correct or incorrect. The alternative ways include paraphrasing, circumlocution, definition and exemplification. Thus, these intralingual strategies can combine both 'avoidance' and 'achievement' at the same time in case of difficulty since the learners avoid what they are not sure of and play it safe by using another form or expression.

One of the strategies listed under 'avoidance' strategies is message adjustment where a learner uses a general word instead of a specific one due to ignorance or complexity. However, as in the case of the use of the other intralingual strategies, the learner conveys the 
message using a vague or less specific word. Another strategy included in 'avoidance' strategies is 'topic avoidance' which entails giving up communication all together or changing the topic. In either case, the problem could be linguistic or conceptual. These topic avoidance strategies are not included in this study due to the use of translation as a data collection tool as we will see later. Thus, this study focuses on cases where the learners do not use a required EFL form or expression and do not use an alternative target language form or expression instead. This operational definition includes cases of code mixing - the use of Arabic words - since the intended concepts and ideas are not expressed in English. The present study is an attempt to quanify and analyse cases where EFL students did not use required words and phrases in their Arabic-English translation.

\section{Data Collection}

Data for this study were collected from 71 Arabic-to-English translations done by 21 male and 50 female Arabic-speaking third-year university English majors with a post-intermediate level of proficiency in EFL. They had to study introductory translation courses mainly for language development purposes. Translation was taught as a task-based EFL learning technique and as a foundation course for those who would study more courses in translation and take up translation as a profession in the future. They were asked to translate short texts (8-10 lines) from English to Arabic in the first half of the semester then from Arabic to English in the second half. The texts were compiled from various sources (books, newspapers, magazines, technical reports, etc.) to cover as many fields of knowledge as possible (science, technology, business, education, etc.). For the purpose of this study, the students were asked to write a one-page essay on social media networks in modern standard Arabic (MSA) in their first class ( 80 minutes) of the first week of the semester to have some idea about their proficiency level in MSA which would be the target language in the first half of the semester and the source language in the second half. Most of the students wrote more than one page and according to the judement of two professors of Arabic most of the MSA essays were well written linguistically and conceptually. Very few essays exhibited some grammatical mistakes related to case marking to indicate the grammatical category of the noun (object, subject, possessive, etc.) The essays were returned to the students with feedback. After discussion of the common errors, the essays were collected and returned again at the end of the semester to be translated into English. The students were not allowed to use any type of dictionaries in translation tests and examinations, hence they were asked to translate their MSA essays without a dictionary in the last class as a rehearsal for the final examination. The students had no idea that they would be asked to translate their own essays from MSA to English at the end of the semester. The students who did not attend the MSA essay writing class or the essay translation class or both classes were not included in the sample.

Translation was used as a data collection tool as a type of guided writing to encourage the students to produce the ideas, forms and structures they used in their MSA essays. As in mental translation when writing in EFL, it is natural for the students to translate their own ideas and language (Cohen, 2011). It is more natural and closer to natural communication than translating other people's language and ideas. To study a phenomenon such as avoidance, the learners need to communicate naturally and express their ideas in their own words and 
structures and have the choice not to produce (1) what they do not know, (2) what they perceive difficult and (3) what they do not want to say. The use of translation of own ideas and language in the present study is a marked departure from the studies where the data were collected from the students' translations of texts prepared by the researchers or by using recognition tests such as multiple-choice questions (see e,g, Mattar, 2003). According to Cohen and Brooks-Carson (2001, p. 171) translation is a type of pushed output where the "students use only the words and expressions readily accessible to them ... and avoid expressions and syntax that they feel are too difficult." These researchers add that the students may attempt to write at a higher level "ending up writing an incomprehensible text or giving up," (p. 171). This is true even when the students translate their own words and ideas from a language they know (e.g. MSA) to a language they are still struggling to learn (e.g. EFL). Translation encourages production and, hence, the use of various compensatory interlingual and intralingual strategies. Nevertheless, translation appears to be more appropriate than free writing as a data elicitation tool to investigate the phenomenon of nonuse in second or foreign language production.

Cohen (2011, p.14) believes the advantage of translation is that it "reduces the load of working memory. Instead of going directly from concepts to their L2 representation, the L2 writers are first expressing the concepts in the L1 and then translating them into the L2." To the best of the present researcher's knowledge, only Elyildirim (2017, p. 236) studied the avoidance strategy by asking the students to express their own ideas in EFL after expressing them in their first language (Turkish). However, what the students actually did was brainstorming and not translating as such. They first wrote a composition in Turkish in the first hour of the writing class. The compositions were then collected and the students were asked to write about the same topic in EFL in the second hour of the class. The researcher thought "the activation of the Turkish version of the memory would lead them to produce the same or similar sentences in the target language," (p. 236). Since the process was not proper translation, there was no guarantee that the students would produce similar, let alone the same, composition. The researcher said the Turkish version was only in the memory, thus turning his tool into a memory test requiring the students to remember what they had said an hour before. If the students were given the Turkish version to translate, they might have produced 'the same or similar' ideas and expressions in EFL. For the puropose of the present study, cases of nonuse (where students did not produce the required words or phrases were quantified. Because it was not possible to know the reason behind their nonuse, the researcher with the help of two EFL instructors met with the students for consultaion. The instructors recorded the reasons given by the students for each case of nonuse in their translation.

\section{Analysis}

A total of 71 students completed the two versions (MSA and EFL) of the text. All of the nonuse instances were counted including cases where the students expressed their ideas using intralingual compensatory strategies such as paraphrasing, definition, and using less specific words. With the help of two bilingual EFL instructors, a total of 624 cases of nonuse were detected of which $483(77 \%)$ were cases where the students expressed their ideas in other 


\section{Ml Macrothink}

words. Here are some examples with the intended words and phrases in brackets translated based on the MSA essays:

- Social media are a double-sided weapon (double-edged sword)

- Social media can be a weapon with two sides.

- Social media are a weapon with two boundaries.

- The problem of social media spread its shades (casts its shadow)

- They are sometimes a piece of heaven or a piece of hell. (a blessing or a curse)

- People use social media to hurt each other. (harm)

- With social media our personal life becomes reachable. (exposed)

- There are habits that do not fit Islamic approaches. (teachings)

- The problems are growing up. (getting worse)

- It helps in spreading wrong images. (rumors)

- The adolescent cannot use technologies (the illiterate)

- People use them to threaten others. (blackmail)

- We have to use the social media smartly. (correctly, properly)

As stated earlier, the production strategies used in the above examples could be due to ignorance or perceived difficulty of the required words and expressions. Of course, in case of ignorance, avoidance is ruled out by definition. In case of perceived difficulty, the learners might have employed a risk avoidance strategy for fear of committing an error in producing the required form or expression which they did not know well. And in doing so, they took the risk of expressing the ideas in other words by using compensatory strategies based on the amount of English they knew. In the remaining 141 (23\%) nonuse cases, the students did not express their ideas in English; they either left out words and phrases or resorted to code mixing. These types of nonuse were observed in 45 English translations. Consultation with the studentsrevealed three reasons for nonuse summarized in Table 1 below.

Table 1. Reasons for nonuse

\begin{tabular}{lll}
\hline Reason & Cases & $\%$ \\
\hline Ignorance and perceived difficulty & 92 & 65 \\
\hline Perceived redundancy & 46 & 33 \\
\hline Memory lapse & 3 & 2 \\
\hline
\end{tabular}

\subsection{Ignorance and Perceived Difficulty}

These were $92(65 \%)$ cases of nonuse where the students could not express their ideas due to language problems, so they dropped words, phrases or whole sentences or resorted to code mixing. In cases where one word was left out, the students either (1) left a gap in the sentence 
and thus in the meaning, (2) kept the sentence in tact but lost a bit of information, or (3) filled the gap with an Arabic word. Here are examples of these three cases:

\subsubsection{Cases 1 and 2: Words Dropped}

- Social media help bring points of views together and ... communication. (facilitate)

- Inventions and scientific developments have ... (increased)

- We will ... discuss the issue of social media. (briefly)

- Radiation activates the brain ... (cells)

- We can use social media positively ... (and constructively)

- Spreading rumors can threaten security ... (and stability)

- Social media have many advantages ... (that cannot be denied)

- I can mention the ... dangers of social media. (possible)

- Scholars can do research ... (and publish it)

- Users should deal with social media with ... care. (utmost)

- This shows our ... failure in using social media. (abject)

\subsubsection{Case 3: Arabic Words}

- Social media applications are silah zu haddain (= double-edged sword)

-These sites do not have any ragaba. (= censorship)

- It is important to tawazon in using social media. (= strike a balance)

- They attack a person's account without ilimihi. (= his knowledge)

- One disadvantage is alibtizaz al aliktoni. (= electronic extortion)

- A person also yantahil other person's character. (= assumes)

Cases where the students reported perceived difficulty were very few compared to those of ignorance. Words and phrases were not produced due to some faint or tentative knowledge of the required form or due to confusion. In the following examples, the italicized parts were left out.

- Social media sites are important and require a high level of awareness and knowledge.

The student confused between 'awareness' and 'consciousness' both of which have one Arabic equivalent.

- If laziness spreads, there will be no achievement and say goodbye to the nation.

The MSA idiomatic expression which means 'say goodbye to the nation' was believed to be difficult to translate into English. 
- These social media programs cause psychological problems such as autism and schizophrenia.

The student knew the word 'schizophrenia' in its spoken form as a loan word used in colloquial Arabic but he did not know how to spell it in English.

- $\quad$ People who are in the social media or virtual reality become more important than people around us.

The student knew about the existence of the expression 'virtual reality' but he was not sure of it.

- We can communicate with people from different nationalities and cultures and ethnicities.

The student had some faint knowledge of the word 'ethnicity'. He was not sure of the meaning nor was he sure of the spelling.

Nonuse of multi-word expressions ranged from two-word phrases to whole sentences which the students could not express in English. In some cases, the student would drop a whole phrase or clause because he did not know or was not sure of only one word in it. In the following examples the italicized parts were not produced.

- Every nation can show its culture and prove itself.

- People use the social media a lot to keep pace with this modern era.

- Social media are used to communicate with people in a way or another.

- It is a double-edged sword and opinions differ based on that.

- People believe in the importance of the social media which cannot be denied.

- These sites lead to the wrong way and loss of identity.

- People should be careful and know the basic rules of safety to be followed.

- Social media connect all people and their awareness and attitudes towards other nations have changed.

- Social media sites affect children badly because they circulate false information or obscene videos and pictures.

- We lost face to face visits and their ancient scent that used to penetrate us.

- Some people use the social media to spread strange ideas and incite others against countries and religions.

\subsection{Perceived Redundancy}

These were 46 (33\%) cases where some words and phrases used in the source (MSA) essays were intentionally dropped from the target (English) version. Consultation with the students 


\section{Macrothink}

revealed that they had thought those words and phrases would not affect the meaning of the sentence. In the following examples, the dropped parts are italicized.

- These sites received a huge acceptance from the people and became ....

- These programs were at first designed for communication.

- We use the social media to know what happens around us in this world

- Children suffer from psychological problems in spite of their young age.

- Social media sites deeply affect societies in this modern era.

- Social media helped spread personal information in writing and pictures.

- The use of these sites causes eye and back problems and so forth.

- For example, we know about global warming and other important issues.

- Social media make people communicate despite the distance between them.

- We know when something bad happens to people in a certain place.

- We need social media these days but we need to use them correctly.

Another reason given for this type of avoidance was that the words and phrases would be a repetition of the meaning expressed by another word or phrase in the sentence. In the following examples, the italicized parts were dropped.

- People do not use the traditional means of communication such as family visits.

- All members of society young and old use the social media.

- Children or young people can use these pictures and videos.

- The social media cause health problems related to the eyes they cause weak eye sight.

- The users can suffer from many health problems; the programs harm eyes, neck and back.

- Some people spread wrong information with no truth in it.

- We use the social media to communicate with the family exchange news and ask about each other.

The italicized parts in the following three examples were reported to have been dropped due to a memory lapse.

- The social media cause a lot of psychological problems.

- We have to put an upper limit to messages.

- People use these media to exchange experience, ideas and information. 


\section{Summary and Conclusion}

The studies that explore the problem of nonuse in EFL production are few especially in the Arab world. This study was intended to add to the previous investigations a new perspective through the use of a more natural data elicitation technique and a quantitative analysis of the data. A marked departure from the previous studies was the clear distinction between avoidance and ignorance and a deeper analysis of the phenomenon of nonuse in EFL production. To that end, 71 Arabic-to-English translations done by third year university English majors were scrutinized. All cases of nonuse (624) were detected, categorized and analyzed. Cases of nonuse where the students expressed their ideas in other words $(483,77 \%)$ were not included. The study focused on the remaining 141 (23\%) cases where no English words were used. These were further grouped and analyzed under three categories: (1) ignorance and perceived difficulty, (2) perceived redundancy, and (3) memory lapse. To distinguish between these three types, the students were consulted for clarification and justification, a procedure which was not followed in the previous studies to the best of the present researcher's knowledge. The findings of this study revealed that most of the cases of nonuse $(65 \%)$ were due to ignorance and perceived difficulty thus indicating gaps in the students' interlanguage. Cases of avoidance amounted to $33 \%$. There were only $3(2 \%)$ cases of memory lapse.

Researchers usually discuss all cases of nonuse under the term 'avoidance'. This study calls for a clear distinction between the EFL words and expressions that the students do not know or are not sure of and those which they know but do not produce due to a memory lapse or because they are deemed unnecessary. This distinction can give a more reliable picture of the phenomenon of nonuse and the real gaps in the students' EFL knowledge, especially when there are cases of intentional nonuse (avoidance) because of perceived difficulty or perceived redundancy. The findings of this study could be useful for the researchers interested in performance analysis and second or foreign language learning. Needless to say, as in the case of the other language learning and communication strategies, instructors can teach and provide feedback in light of the areas of ignorance and difficulty revealed by the instances of nonuse, (for more information on strategy-based teaching see e.g. Lam, 2010; Maleki, 2010; Teng, 2012). However, cases of nonuse may not be easy to detect in free writing, the kind of writing that second or language learners do most of the time. Hence, the technique of having students express their ideas in their first language and translate them into the second or foreign language can help in this respect.

It is worth mentioning here that if the students who participated in this study were told that they would translate their MSA essays into English, they might have used simpler MSA words and less idiomatic expressions. Also they might have avoided some concepts and ideas and written shorter essays, thus minimizing the likelihood of nonuse in English. Translation encourages production and, hence, the use of various compensatory interlingual and intralingual strategies. Nevertheless, translation appears to be more appropriate than free writing as a data elicitation tool to investigate the phenomenon of nonuse in second or foreign language production. 


\section{Mll Macrothink}

International Journal of Linguistics

ISSN 1948-5425

2020, Vol. 12, No. 4

The study attempted to address the limitations of the previous studies with regard to the data collection instrument, the confusion between 'avoidance' and 'ignorance', and between nonuse and achievement by using other words, and the lack of statistical analysis with adequate examples to show the magnitude of and the reasons behind the different types of nonuse. Further studies are needed to shed more light on the phenomenon of nonuse with larger samples, different EFL proficiency levels, different first languages and different writing topics. Further studies are needed also to show the magnitude of nonuse - due to ignorance and difficulty - in relation to the other types of grammatical and semantic errors committed as a result of the use of interlingual and intralingual achievement strategies.

\section{References}

Abu-Jamil, B. (2010). Rethinking avoidance of English phrasal verbs by Arab learners. $M A$ Thesis, Colorado University, Colorado.

Aldukhayel, D. (2014). The L2 exposure effect on avoidance of phrasal verbs by Arab ESL learners. MA Thesis, Colorado State University, Colorado.

Aliakbari, M., \& Allvar, N. (2009). Communication strategies in the written medium: The effect of language proficiency. Linguististik Online, 40, 3-12.

Alqarni, I. (2018). Saudi English major freshman students' vocabulary learning strategies. International Journal of Applied Linguistics and English Literature, 7(1), 141-145. https://doi.org/10.7575/aiac.ijalel.v.7n.1p.141

Chen, J. (2007). On how to solve the problem of the avoidance of phrasal verbs in the Chinese context. International Education Journal, 8(2), 348-353.

Chuin, T., \& Kaur, S. (2015). Types of language learning strategies used by tertiary English majors. TEFLIN Journal, 26, 17-35. https://doi.org/10.15639/teflinjournal.v26i1/17-35

Cohen, A. (2011). Strategies in Learning and Using a Second Language. London: Routledge.

Cohen, A., \& Brooks-Carson, A. (2001). Research on direct versus translated writing. The Modern Language Journal, 85(2), 169-188. https://doi.org/10.1111/0026-7902.00103

Darus, S., \& Subramanian, K. (2009). Error analysis of the written essays of secondary school students in Malaysia. European Journal of Social Sciences, 8, 483-495.

El-Marzouk, G. (1995). Avoidance or some other strategies: A case for the passive in Arabic and English. The Irish Yearbook of Applied Linguistics, 15, 113-125.

Elyildirim, S. (2017). Avoidance strategy in foreign language production. Journal of S. D. University Institute of Social Sciences, 28, 231-242.

Ghabanchi, Z., \& Goudarzi, E. (2012). Avoidance of phrasal verbs in learner English. World Journal of English Language, 2, 43-54. https://doi.org/10.5430/wjel.v2n2p43

Kharitonova, A. (2013). Lexical transfer and avoidance in the acquisition of English phrasal verbs. MA Thesis, University of Oslo, Norway.

Koo, J. (2011). The avoidance of phrasal verbs: Comparing Korean learners of English with German English learners. Postgraduate Research Forum on Linguistics, 13-14, 165-182. 


\section{Macrothink}

International Journal of Linguistics

ISSN 1948-5425

2020, Vol. 12, No. 4

Lam, W. (2010). Implementing communication strategy instruction in the ESL classroom. TESL Canada Journal, 27(2), 11-30. https://doi.org/10.18806/tesl.v27i2.1056

Liao, Y., \& Fukuya, Y. (2004). Avoidance of phrasal verbs: A case of Chinese learners of English. Language Learning, 193-226. https://doi.org/10.1111/j.1467-9922.2004.00254.x

Llach, M. (2011). Lexical Errors and Accuracy in Foreign Language Writing. Bristol: Multilingual Matters. https://doi.org/10.21832/9781847694188

Mahmoud, A. (2013). Errors in error analysis. Scottish Journal of Arts, Social Sciences and Scientific Studies, 10(2), 52-64.

Mahmoud, A. (2019). Interlingual transfer of intralingual errors: Lexical substitution. Studies in English Language Teaching, 7(4), 419-431. https://doi.org/10.22158/selt.v7n4p419

Maleki, A. (2010). Techniques to teach communication strategies. Journal of Language Teaching and Research, 1(5), 640-646. https://doi.org/10.4304/jltr.1.5.640-646

Mattar, A. (2003). Is avoidance ruled out by similarity?. Poznan Studies in Contemporary Linguistics, 38, 103-115.

Mayor, M. (1995). Longman Dictionary of Contemporary English. Harlow: Longman.

Sirkovic, N., \& Kovac, M. (2017). Communication strategies in use. Studies in English Language Teaching, 5(1), 24-33. https://doi.org/10.22158/selt.v5n1p24

Siyanova, A., \& Schmitt, N. (2007). Native and non-native use of multi-word vs one-word verbs. International Review of Applied Linguistics in Language Teaching, 45(2), 119-139. https://doi.org/10.1515/IRAL.2007.005

Teng, H. (2012). The teachability of EFL communication strategies. Procedia-Social and Behavioral Sciences, 46, 566-570. https://doi.org/10.1016/j.sbspro.2012.06.106

Vazquez, M. (2005). Avoidance as a learning strategy. Estudios Ingleses de la Universidad Complutense, 13, 67-83.

Zare, P. (2012). Language learning strategies among EFL/ESL learners: A review of literature. International Journal of Humanities and Social Sciences, 2(5), 162-169.

Zhang, Y. (2007). Communication strategies and foreign language learning. US-China Foreign Language Teaching, 5(4), 43-48.

\section{Copyrights}

Copyright for this article is retained by the author(s), with first publication rights granted to the journal.

This is an open-access article distributed under the terms and conditions of the Creative Commons Attribution license (http://creativecommons.org/licenses/by/4.0/) 